\title{
Consumers' Behavior toward Green Products: A Signalling Theory Approach
}

\author{
Rosamartina Schena ${ }^{1}$, Giulia Netti ${ }^{1} \&$ Angeloantonio Russo ${ }^{1}$ \\ ${ }^{1}$ Department of Management, LUM Jean Monnet University, Casamassima (BA), Italy \\ Correspondence: Angeloantonio Russo, Professor of Management, Department of Management, LUM Jean Monnet \\ University, Casamassima (BA), Italy. Tel: 39-80-697-8111.
}

Received: September 11, 2015

Accepted: October 5, 2015

Online Published: October 31, 2015

doi:10.5430/ijba.v6n6p44

URL: http://dx.doi.org/10.5430/ijba.v6n6p44

\begin{abstract}
Marketing is changing over time, giving value not only to customer satisfaction but also to environmental heritage, for a sustainable economy. The importance of the natural environment related to marketing brought many academics and professionals to define green marketing, although today there is nota unique definition. Relaying on the signaling theory, this study aims at investigating the relationship between the signals, which are changeable factors and activities conveying information to individuals in order to bridge the gap, and the consumers' attitude as a feedback to these signals. Results shown that firms already making green products and/or green production processes to continue along this path and continue innovation. Conversely, firms that still do not understand the change of course of society and the future changes in consumers' purchasing behavior, should divert their forces and their expertise in this direction.
\end{abstract}

Keywords: consumer behavior, green marketing, green products, signalling theory

\section{Introduction}

In the course of historical evolution of enterprises, markets and consumers birth, the art of signals communication and understanding has been part of the well-defined marketing field. No competitive structure would exist without it, no consumer would be satisfied without a previous understanding of his/her conscious and unconscious needs and demands, whereas, if the market did not comply with the evolutionary dynamics of the environment and society, it would not respect its role and would implode.

Marketing is the process of planning and executing the conception, pricing, promotion, and distribution of ideas, goods, and services to create exchanges that satisfy individual and organizational objectives. This definition, however, does not meet the reality as a key element is missing, that is the social process. Taking into consideration such process, the Marketing activity turns out to be a tool to understand, create, communicate and distribute value (Kotler, 1962). The concept of marketing is updated and no longer connected to the mere economic process; it also refers to the social process, obtaining an advantage not only for the company, but for consumers and society as a whole. Bearing in mind that time does not stop and that the evolution of the society continues day after day affecting all market players, marketing is changing over time, giving value not only to customer satisfaction but also to environmental heritage, for a sustainable economy (World Commission Environment and Development, 1987). Within this context, the concept of green marketing is rising momentum, providing evidence of a need for additional efforts in the strategic management field, in order to investigate the consumers' perspective towards sustainability and, among the others, the so-called eco-friendly products.

This study aims at investigating the relationship between the signals, which are changeable factors and activities conveying information to individuals in order to bridge the gap, and the consumers' attitude as a feedback to these signals.

From the study conducted and the results obtained, it seems appropriate to remind firms already making green products and/or green production processes to continue along this path and continue innovation. Conversely, firms that still do not understand the change of course of society and the future changes in consumers' purchasing behavior, should divert their forces and their expertise in this direction, not to be left out of the games. 


\section{Theory and Hypotheses}

\subsection{A Signaling Theory Approach to Green Marketing}

The importance of the natural environment related to marketing brought many academics and professionals to define green marketing, although today there is not a unique definition. Firstly, green marketing was defined as the study of the positive and negative aspects of marketing activities on pollution, energy depletion and non-energy resource depletion (Henion and Kinnear, 1976). Such definition is rough and incomplete, compared to the overall field of marketing operation and peculiarities, and it does not include, among the others, customer satisfaction.

At the same time, different authors have dealt with additional definitions. In some cases, scholars considered green marketing as all the activities designed to generate and facilitate any exchanges intended to satisfy human needs or wants, such that the satisfaction of these needs and wants occurs, with minimal detrimental impact on the natural environment (Polonsky, 1994). Others defined green marketing as the application of marketing tools to satisfy organizational and individual goals in such a way that the preservation, protection and conservation of the physical environment is upheld (Mintu and Lozada, 1993). Stanton and Futrell (1987) describe green or environmental marketing as all activities designed to generate and facilitate any exchanges intended to satisfy human needs or wants with minimal harmful impact on our environment.

Nevertheless, recent literature highlighted consumers pay more and more attention and interest in environmental issues, and, in some cases, they even change their attitude towards green products (Pickett-Backer and Ozaki, 2008; Pogutz et al., 2009). Moreover, whether products are made in factories, brands are instead, produced in the consumers' minds; that is why the consumer is gaining an increasingly important role. Some researches has shown that this growing interest in environmentally sustainable products has led consumers to be willing to pay more for green products rather than non-green ones (Griskevicius, Tybur and Van den Bergh, 2010; Vurro et al., 2014).

Nevertheless, consumers are not necessarily pro-green and changes in their attitudes depend on corporate reliability (Goldsmith, Lafferty and Newell, 2000). Hutcherson and Gross (2011) reveal how environmental degradation and pollution can be considered significant and cause anger in environmentally aware people, as concerned for themselves and for the future life of their loved ones. On the other hand, the consumers are not only attentive to environmental issues, but also to the product characteristics and quality.

Over the past 10 years, several studies have been conducted in order to understand how consumers perceived green products, and from a first analysis (Bourk and Prescott, 2002) green products were considered qualitatively lower than non-green products. Recent research shows an improvement in green products quality, which consequently led to the rise of attitude changes toward them (Pickett-Baker and Ozaki, 2008).Therefore, as noted by Luchs, Naylor, Irwin, and Raghuna (2010), a main characteristic influencing consumers when evaluating green products is the opinion about their effectiveness.

This topic calls into question corporations, which not only need to highlight their green products quality but should also avoid the false behavior of greenwashing, in order not to lose trustworthiness and risk harm to the brand image. Greenwashing is likely to increase the skepticism of consumers towards products advertised with the use of environmental messages. Connelly, Ketchen and Slater (2011) suggest that firms willing to differentiate their offerings and to achieve a competitive advantage by investing in green products need to invest in certifications, environmentally friendly technologies and use green packaging. In other words, firms should represent a clean and environmentally sustainable product so that they are not linked to greenwashers.

In terms of corporate sustainability, companies should focus not only on economic, but also on social and environmental values. Hence, they should try to achieve a balanced approach between people, profit and planet (Elkington, 2004). Therefore, an identity built around corporate sustainability improves the consumers' beliefs towards the brand ability to provide additional functional benefits (Sen and Bhattacharya, 2007).

It is therefore critical to note that firms and consumers are two sides of the same coin, sharing information and decisions on the attitude and willingness to close a purchase. Within an environmental-oriented context, as described above, information is the critical asset that firms should be able to clearly transfer to the consumer. In this study, therefore, what can be considered as green information take the floor, and are operation alized as the signal that consumers match to drive their decision making process.

Relying on the work by Spence (1973) referring to emerging signaling theory, we assume that companies make wrong choices, and it is therefore necessary to identify an observable character - the signal - which allows to reduce the risk linked to the decisions. Obviously, this risk is associated with an opportunity cost, a monetary value or not, to be borne in order to guide managers' strategic decision-making choices. Karasek and Brayant (2012) consider the 
impact of Spence's theory in three different areas: management, psychology and science. According to Bolding (1993), offering a warranty is a way to signal to the customer that your product is superior when asymmetric information is present, and he has to choose in his consideration set. Kirmani (1990) suggests that firms can signal on advertising, a strong tool that can increase perceived quality in choosing the product.

A different stream of research considers the brand name as an opportunity through which the company will increase the consumers' perceived value, fueling the brand equity (Lambin, 2004). Therefore, brand is the signal, that means the value-added that customers expect and that will be decisive for future purchases.

However, considering an environmental friendly attitude, attention has to be paid to the signals that companies decide to use to represent the opportunity costing the green marketing. As an example, advertising is a means of information and promotion of green products, which has been typically observed by consumers over the years in a skeptical way (Bickart and Ruth, 2012; Shrum, McCarty and Lowrey, 1995).

Taking into account the literature on green marketing and signaling theory, research questions are investigated in this study putting new emphasis on some specific signals. Moreover, we establish if, and to what extent such signals do influence the consumer and which of specific signal is more important for the consumer. Research questions are specified as follows.

$\mathrm{RQ1}$. Is the consumer proactive to green marketing?

RQ2. Do differences exist among consumers when purchasing green products?

RQ3. If yes, do differences on in behavior and attitude depend on specific factors, such as social class or age?

\section{Methodology}

\subsection{The Questionnaire}

The methodology used in our study based on three different research tools, questionnaires, focus groups and survey, which have found their focus in the household cleaning sector. The questionnaire has been carried out through twenty questions - open-ended, multiple choice and dichotomous questions - divided into three main categories (i.e., brand, cost and perception), to each of which were attributed different signals.

Table 1. The questionnaire

First category: Brand

1) What brand of detergent do you regularly use for laundry?

2) Which of these is a "green" detergent?

3) What is your main driver when purchasing laundry detergent? Price; Quality; Discount-Promotion; Brand; Packaging; Other...

4) Do you change brand of detergent: Frequently; Often; Never

Second category: Cost

5) When buying a detergent, it is important: cleaning result; respect for the environment; low cost; other

6) Would you be interested in buying an organic detergent? Yes; No

7) Why?

8) When buying a detergent, do you care about the product (and production processes) guarantees in terms of health, safety and environmental protection? Yes;

No

9) Would you require more clear and precise information on the product features on company websites? Yes; $\quad$ No

Third category: Perception

10) Would you be willing to revise your consumption / use habits in favor of more sustainable products? Yes; No

11) Regarding environmental issues, would you define yourself as a consumer? Conscious and active; Conscious and passive; Disinterested and unaware. 
12) When you see a new detergent on the supermarket shelf: I like trying new products and I purchase it; I think it's an expedient to making me spend money; I'll buy it only if it responds to my needs.

13) Have you ever seen advertisements for "green" detergents (environmentally, recycling and consumption friendly)?Yes; No

\begin{tabular}{ll}
\hline 14) & If so, what brand? \\
\hline 15) & Do you think there are? Few; Enough; Many. \\
\hline 16) & What type of detergent do you usually purchase? Powder detergent; Detergent capsule; Detergent \\
& on tap. \\
\hline 17) & Why? \\
\hline
\end{tabular}

\section{Test Questions}

\begin{tabular}{lll}
\hline 18$)$ & Do you usually change brand of detergent? Yes; & No \\
\hline 19) & Would you buy detergents on tap? Yes; $\quad$ No & \\
\hline 20) & Why? & \\
\hline
\end{tabular}

As gathered from the Brand category, the questions refer on buying habits, including the type of detergent used and the frequency of purchase, determining the consumer level of involvement and the type of problem solving. The issue of Costs provides potential elements to invest in, in order to reduce the cognitive dissonance in a vast and saturated field as household cleaning. Lastly, the Perception category questions identify the level of attention and interest in green issues in consumer habits.

\subsection{The Focus Group and the Survey}

Two focus groups, respectively labelled as Focus Young and Focus Old, have been run. Focus Young involved up of five people aged between twenty and thirty years, including both men (2) and women (3).Focus Old consisted of five people, all women, aged between thirty and fifty years.

Firstly, a short questionnaire was sub mitted to each individual (see Table 2), consisting of three questions expressing the degree of interest and information about the problems.

Table 2. Focus introductory questionnaire

\begin{tabular}{llllll}
\hline Age & & & & & \\
Gender $\quad$ M & & & & \\
Qualification School-leaving certificate Degree & & & & \\
1) How interested you are in the following topics: & & & & \\
- Desertification & & & & \\
- Air pollution & 1 & 2 & 3 & 4 & 5 \\
- Water pollution & 1 & 2 & 3 & 4 & 5 \\
- Shortage of resources & 1 & 2 & 3 & 4 & 5 \\
- Biodiversity & 1 & 2 & 3 & 4 & 5 \\
- Waste disposal & 1 & 2 & 3 & 4 & 5 \\
- Toxicity (dangerous chemical productions) & 1 & 2 & 3 & 4 & 5 \\
- Greenhouse effect and climate changes & 1 & 2 & 3 & 4 & 5 \\
- Global warming & 1 & 2 & 3 & 4 & 5 \\
- Food quality & 1 & 2 & 3 & 4 & 5 \\
- Recycling & 1 & 2 & 3 & 4 & 5 \\
- Illegal dumping and land degradation & 1 & 2 & 3 & 4 & 5 \\
- Polluting plants & 1 & 2 & 3 & 4 & 5 \\
2) How informed do you feel? & 1 & 2 & 3 & 4 & 5 \\
3) Do you think more awareness campaigns could be useful? If so, why? & 1 & 2 & 3 & 4 & 5 \\
\hline
\end{tabular}


After answering the introductory questionnaire, a thirty-minute debate was opened to discuss the interviewees' habits and different opinions with the help of the questionnaire and some other questions. Subsequently, the interviewees watched four commercials related to the previously mentioned products, selected by popularity, after which we took note of the feedbacks.

As a last step of the methodology, the survey has been carried through the web, submitting the questionnaire on most popular social networks (Facebook, Twitter and WhatsApp), collecting fifty responses.

\section{Findings}

\subsection{Focus Young}

The five individuals aged between twenty and thirty years, part of Focus Young, were very active, involved and interested on this matter, and had a dynamic debate. The analysis has been divided into three main moments: introduction to the focus, discussion and feedback to commercials. The general level of interest is medium-high, in fact seven topics recorded three preferences, while the issue of food quality recorded the highest preference, with anoverall level equivalent to four or five. Nevertheless, knowledge of these issues was not high, and consequently, more appropriate awareness campaigns would have been appropriate. As a result, based on the answers to the open-ended questions about awareness campaigns, some early signals have been identified (see Figure 1).

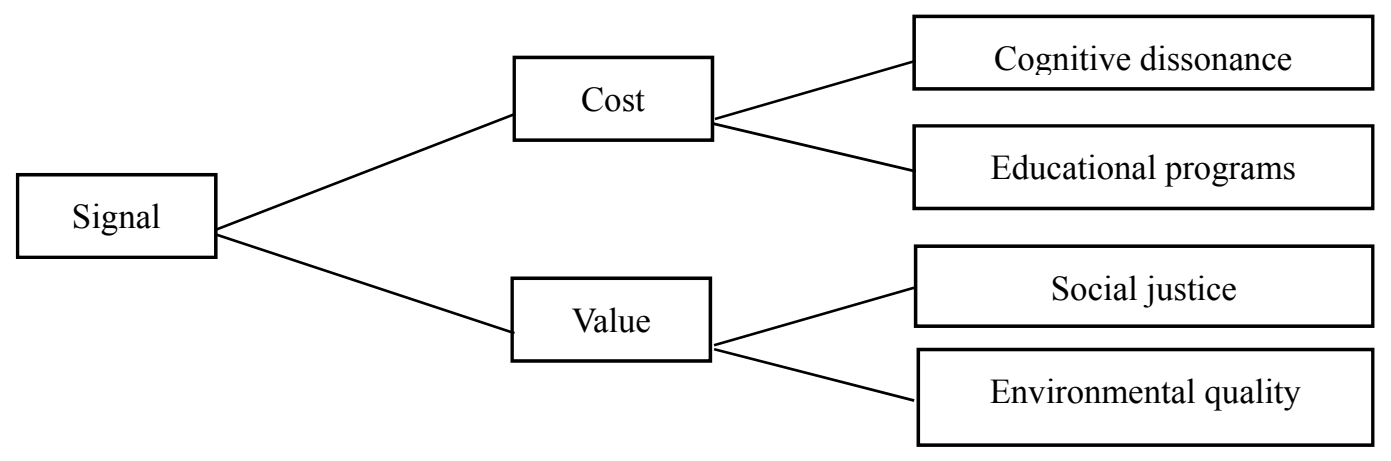

Figure 1. Signals from awareness campaigns

In reference to the brand, it can be seen that the most used detergent is Dash liquid, whose popularity induce the purchase intentions among consumers. Such popularity seems to convey functionality, efficacy and guarantee, as well as the best value for money. The high level of brand loyalty was unanimous, with the exception of only a girl who bought a new detergent, but could not remember the brand.

During the debate, it emerged that younger people do not give any real importance to the purchase of an organic detergent, but in any case, they would not rule out the purchase if they had more information and guarantees on the environmental impact.

In terms of perception, the debate highlighted the possibility to change their consumption and use habits in favor of more sustainable products

In addition, three out of five people said to be aware and active consumers, but they acknowledge that changing their habits would entail a premium price they cannot afford at the present, but don't exclude to experience that in the future.

Concerning the issue of detergents on tap, a question emerged during the debate highlighted a clear hesitation using products served on tap. The group perceived detergents on tap as less expensive, without brand, and with no guarantee of reducing environmental impact.

From the viewing of the commercials, it emerged that Dash was immediately recognized and that the presence of a celebrity inspires security and guarantee of effectiveness. Deox detergent commercial highlighted concerns about the type of advertising, similar to many other. Dixan and Winni's detergents commercials did not convey any memory or feeling. At the end of the debate, however, the group responded in a positive way, not excluding the possibility of changing their habits in the near future. 


\subsection{Focus Old}

Five women aged between the thirty and fifty years participated in this focus. The procedure followed was the same as in the focus young. It was found that the elder interviewees' interests was very high: in fact, they showed the maximum level of interest in eight out of thirteen subjects. Nevertheless, they admitted that such issues are not well known and it was necessary to increase awareness campaigns.

From this first step, elder and younger interviewees shown different positions, but actually, analyzing the answers to the open-ended question, they seemed to share the same concerns. A second set of signals emerged, which reflected the same indications for the above discussed signals from the Focus Young (refer to Figure 1).

Regarding the Brand, it emerged that all five women habitually use Dash, which offers a good value for money and therefore satisfies their primary requirement. However, they recognize that it may be important to protect the environment using organic products, but require more information and guarantees on the product safety and environmental impact. Nevertheless, only one person admitted she tried Winni's and was not satisfied.

The issue about detergents on tap was proposed again, and the elder group consider them not handy and not reliable. The possible advantages of using detergents on tap do not change their habits. From the viewing of the commercials, it emerged that Dixan and Deox did not convey any memory, whereas they reminded Winni's commercial but did not recognize the quality of the product. The high level of Dash reliability was recognized through the advertising and the presence of a celebrity as a guarantee of product effectiveness and security.

\subsection{Survey}

Considering the survey, the analysis was performed on categories of questions. In the Brand category, $70 \%$ of respondents use the Dash, which seems to meet the most important need: ensuring the cleaning result promised. The determining factor for consumers' purchasing decisions varies depending on the detergent used. In fact, for those buying Dash, the main feature is quality, as well as for the only person who buy Winni's. For Dixan, General and Sole detergents the determining factor is the price. The level of involvement has not been clearly defined. $44 \%$ of the respondents affirmed they never change detergent, while the remaining $56 \%$ changes it frequently.

The Cost category questions showed that the majority of respondents consider the purchase of an organic detergent to be important; for that reason, they would be willing to change their use and consumption habits in favor of more sustainable products. There is, therefore, a strong desire to respect the environment, protect the children's future and to use a high quality product. Only $12 \%$ of the participants expressly stated that they would never adopt an organic detergent, due to the premium price and to a greater attention to the cleaning rather than to the environment.

The interviewees required more and clearer information on the product features, on its production process, as well as on the benefits arising from it, in order to change their consumption habits. For $76 \%$ of respondents, such information should be available on business websites. However, as many as $44 \%$ of respondents described $\mathrm{him} / \mathrm{h}$ erself as a conscious but passive consumer. Ultimately, it seemed that there may be, in the consumers' future habits, the possibility of new forms of purchase. The signals expressed by respondents can be summarized as follows (see Figure 2).

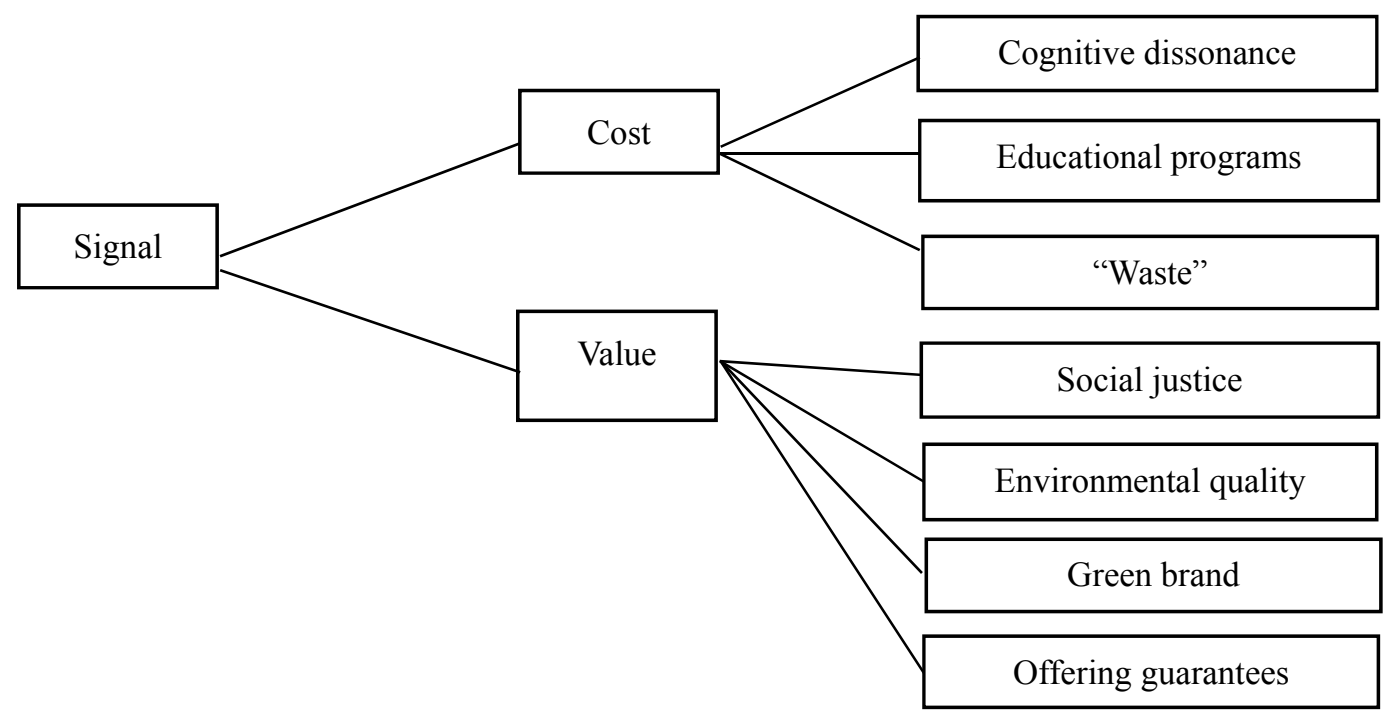

Figure 2. Signals from the survey 
In terms of perception, although $54.3 \%$ of respondents stated to have seen a commercial for environmentally, recycling and consumption friendly detergents; only half of them was able to specify the name (Winni's $24 \%$, Chanteclair 2\%). Furthermore, the analysis shown that green products advertising are few.

Surprisingly, the detergent on tap met with a $60 \%$ public approval. The reasons can be explained by the fact that the respondents using liquid detergents, because handier or simply less expensive, seem more willing to make a new habit. In fact, some of the respondents already use detergent capsules because those are considered more efficient and less polluting, due to the lower use of containers. The remaining $40 \%$ expressed a dislike for detergents on tap, and explained the reasons of such position with the inconvenience, the uncertainty about the results as well as the absence of certificates attesting the respect for the environment.

\section{Discussion and Implications}

To realize what shade of green the respondents belong, their answers, their behaviors, attitudes and considerations have been given to the signals of the Green Signal Chart and then compared with the shades of green consumer. Taking into account the purchasing behavior of the younger group, their answers and signals, the following shade of green resulted, labelled as medium green (see Figure 3).

With reference to the elder group, the balance of separation is still very difficult to achieve (Spence, 1973). The messages they receive are not well coded and appear to be tinged with greenwashing, because their beliefs are not followed by concrete actions, deducing that their attitude is not prone towards environmental innovation. A light green-labelled shade therefore emerged (see Figure 4).

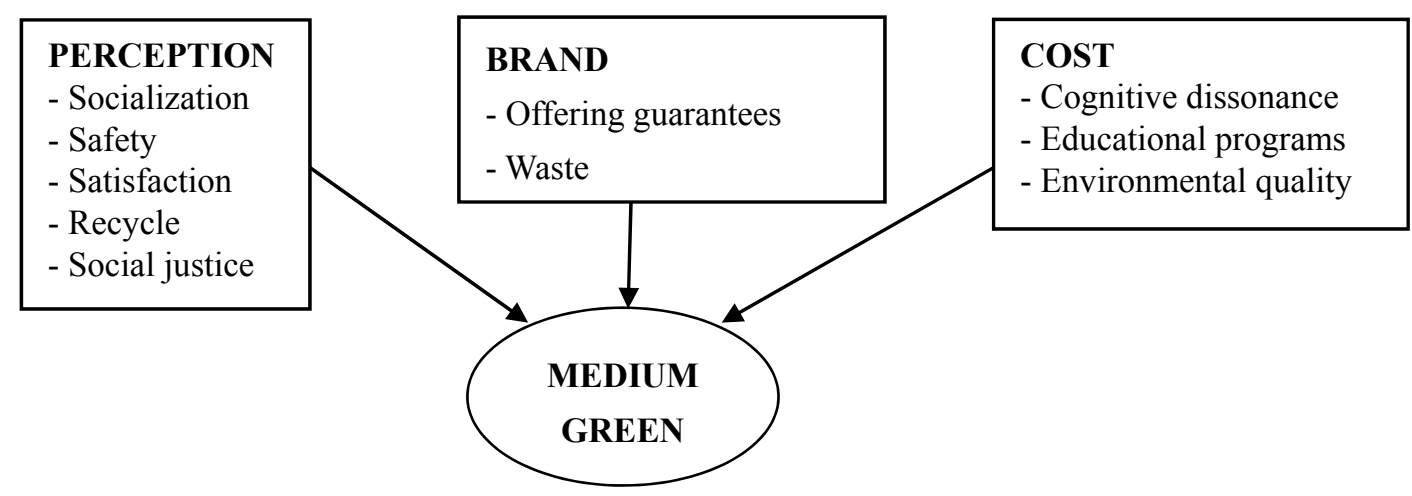

Figure 3. Medium green

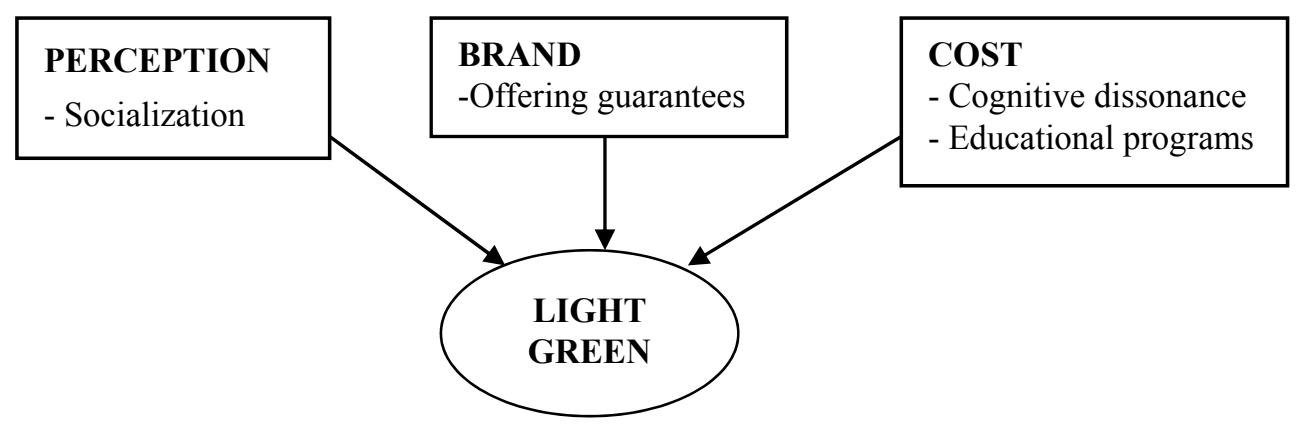

Figure 4. Light green

The survey respondents expressed a higher flexibility and ability to adapt to new environmental requirements than previously seen. They react proactively to the possibility of adopting new use and consumption habits of green products, both on tap and organic. The increased environmental awareness, driven by a sense of moral responsibility towards future generations, highlights their inclination to adopt eco-friendly alternatives for a sustainable future. Therefore, a last dark green-labelled shade can be highlighted (see Figure 5). 


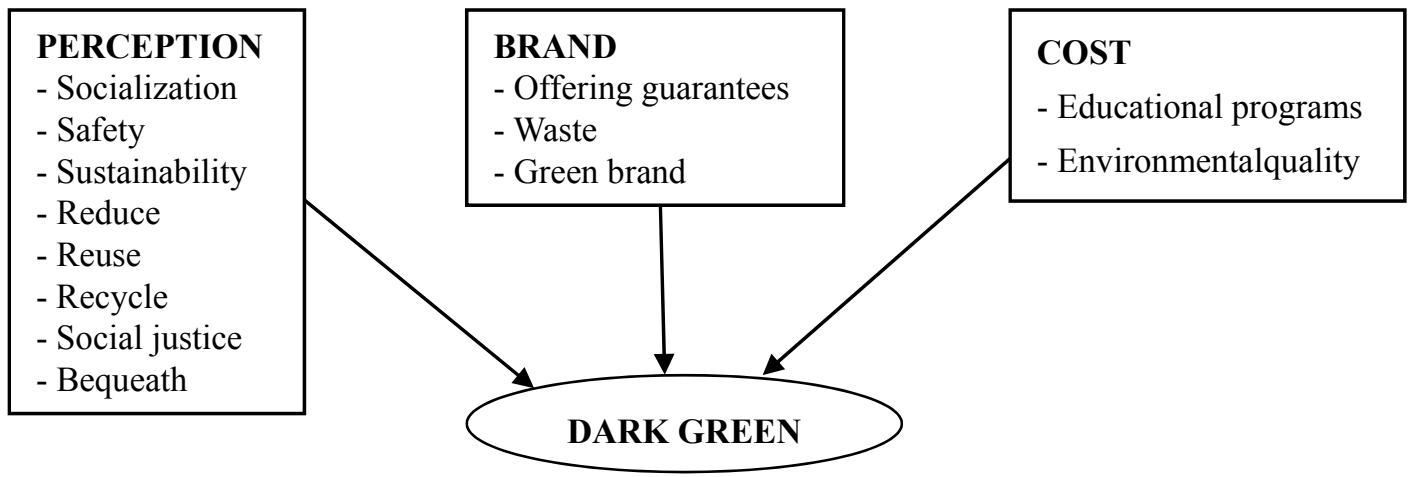

Figure 5. Dark green

\subsection{The Green Consumer Matrix}

Reprocessing the overall data obtained from the analysis, we have developed a consumer type profiles matrix highlighting the main differences and peculiarities. The fulfillment of the matrix was carried out by identifying the main variables of research: signals and shades of green (Table 3 ).

Table 3. Green consumer matrix

\begin{tabular}{|c|c|c|c|}
\hline $\begin{array}{l}\text { SIGNAL / } \\
\text { GREEN }\end{array}$ & LIGHT GREEN & MEDIUM GREEN & DARK GREEN \\
\hline Cost & $\begin{array}{l}\text { - cognitive dissonance } \\
\text { - educational programs }\end{array}$ & $\begin{array}{l}\text { - cognitive dissonance } \\
\text { - educational programs } \\
\text { - environmental quality }\end{array}$ & $\begin{array}{l}\text { - environmental quality } \\
\text { - educational programs }\end{array}$ \\
\hline Perception & $\begin{array}{l}\text { - socialization } \\
\text { - recycle }\end{array}$ & $\begin{array}{l}\text { - socialization } \\
\text { - safety } \\
\text { - satisfaction } \\
\text { - recycle } \\
\text {-social justice }\end{array}$ & $\begin{array}{ll}\text { - } & \text { socialization } \\
\text { - } & \text { safety } \\
\text { - } & \text { sustainability } \\
\text { - } & \text { reduce, reuse, recycle } \\
\text { - } & \text { social justice } \\
\text { - } & \text { bequeath }\end{array}$ \\
\hline Brand & - offering guarantees & $\begin{array}{l}\text { - offering guarantees } \\
\text { - waste }\end{array}$ & $\begin{array}{l}\text { - offering guarantees } \\
\text { - waste } \\
\text { - green brand }\end{array}$ \\
\hline
\end{tabular}

Ultimately, the identification of the three main categories of signals - Cost, Perception, Brand -, and the studies previously carried out by Spence (1973), allowed us to identify the cost Signals distinguishing the green economy. Moreover, adding the study of the shades of green, we have defined the three types of consumers based on their purchasing behavior.

In the case study, the Focus Old group is associated with Light Green category, since, although the elders are aware of their role at the time of purchase and they are positive towards new models, they remain skeptical and clearly not ready to change their habits. They have a critical attitude towards the results that companies can achieve by focusing on green products. There is hence the necessity for companies to intervene and invest on the consumers' cognitive and informational dissonance.

Contrariwise, the Focus Young group is aware about the role it can play through the purchase of socially and environmentally responsible products, but, nevertheless, still need some incentive (e.g., convenience) to purchase 
them. The perception of the younger is noticeably higher; the social justice component is strong and allows discussing about the future buying habits. The proactive and dynamic attitude is a sign of willingness to change, a fundamental element to bear in mind, as tomorrow's firms will have to meet with this type of consumer.

Finally, the survey respondents have innovation in the blood, showing that the cultural revolution has begun and the sense of responsibility towards future generations is becoming increasingly urgent and real. The perception of green products is rising, the possibility that environmental issues will condition the consumers' purchasing behavior, and use is becoming more and more tangible.

From the study conducted and the results obtained, it seems appropriate to remind companies already making green products and/or green production processes to continue along this path and continue innovation. Conversely, firms that still do not understand the change of course of society and the future changes in consumers' purchasing behavior, should divert their forces and their expertise in this direction, not to be left out of the games.

\section{References}

Bickart, Barbara A., \& Julie A. Ruth. (2012). Green Eco-seals and advertising persuasion. Journal of advertising, 41(4), 51-67. http://dx.doi.org/10.1080/00913367.2012.10672457

Bourk, Diane, \& John Prescott. (2002). A Comparison of the Nutritional Value, Sensory Qualities, and Food Safety of Organically and Conventionally Produced Foods. Critical Reviews in Food Science and Nutrition, 42(1), 1-34. http://dx.doi.org/10.1080/10408690290825439

Carrete, Castaño L., Felix R., Centeno R., \& González E. Eva. (2012). Green consumer behavior in an emerging economy: confusion, credibility, and compatibility. Journal of consumer marketing, 470-481.

Chan Yu-Shan, \& Chang Ching-Hsun. (2013). Greenwasch and green trust: the mediation effects of green consumer confusion and green perceived risk. Journal of Business Ethics. http://dx.doi.org/10.1007/s10551-012-1360-0

Connelly, B. L., Ketchen, D. J. Jr., \& Slater, S. F. (2011). Toward a 'theoretical toolbox' for sustainability research in marketing. Journal of the Academy of Marketing Science, 39, 86-100. http://dx.doi.org/10.1007/s11747-010-0199-0

Cronin, J. J., Smith, S., Glein, Mark R., Ramirez, E., \& Martinez, J. D. (2010). Green marketing strategies: an examination of stakeholders and the opportunities they present. Academy of Marketing Science.

Du, Shuili, Bhattacharya, C. B., \& Sankar Sen. (2007). Reaping Relational Rewards from Corporate Social Responsibility: The Role of Competitive Positioning. International Journal of Research in Marketing, 24(3), $224-41$.

Elkington, J. (2004). The triple bottom line, does it all add up?: assessing the sustainability of business and CSR. Earthscan.

Goldsmith, Ronald E., Barbara A. Lafferty, \& Stephen J. Newell. (2000). The Impact of Corporate Credibility and Celebrity Credibility on Consumer Reaction to Advertisements and Brands. Journal of Advertising, 29(3), 43-54. http://dx.doi.org/10.1080/00913367.2000.10673616

González Eva M., Felix Reto, Carrete Lorena, Centeno Edgar, \& Casta- Raquel. (2015). Green Shades: a segmentation approach based on ecological consumer behavior in an emerging economy. Journal of marketing theory and practice, 23, 287-302. http://dx.doi.org/10.1080/10696679.2015.1032395

Griskevicius, Vladas, Joshua M. Tybur, \& Bram Van den Bergh. (2010). Going Green to Be Seen: Status, Reputation, and Conspicuous Conservation. Journal of Personality and Social Psychology, 98(3), 392-104. http://dx.doi.org/10.1037/a0017346

Heijnen, P., \& Van Der Made A. (2012). A signalling theory of consumer's boycotts. Journal of Environmental Economics \& Management, 404-418.

Hutcherson, Cendri A., \& Gross, James J. (2011, April). The moral emotions: A social-functionalist account of anger, disgust, and contempt. Journal of Personality and Social Psychology, 100(4), 719-737. http://dx.doi.org/10.1037/a0022408

Karasek, R. III., \& Bryant, P. (2012). Signaling Theory: Past, Present, and Future. Academy of Strategic Management Journal, 11(1), 91-99.

Karl, E. Henion, \& Thomas C. Kinnear. (1976). Ecological Marketing. American Marketing Association. 
Kirmani, A. (1990). The Effect of Perceived Advertising Cost on Brand Perceptions. Journal of Consumer Research, 17. http://dx.doi.org/10.1086/208546

Kotler, P. (1962, April). A Generic Concept of Marketing. Journal of Marketing, 36, 46-54.

Kotler, P. (2011, July). Reinventing marketing to manage the environmental imperative. Journal of Marketing, 75, 132-135. http://dx.doi.org/10.1509/jmkg.75.4.132

Kronroda, Grinstein A., \& Wathieu L. (2012). Go green! Should environmental messages be so assertive?. Journal of Marketing, 76, 95-102. http://dx.doi.org/10.1509/jm.10.0416

Lambin, J. J. (2004). Market-driven Management. McGraw Hill.

Luchs, M. G., Naylor, R. W., Irwin, J. R., \& Raghunathan, R. (2010, September). The sustainability liability: Potential negative effects of ethicality on product preference. Journal of Marketing, 74, 18-31. http://dx.doi.org/10.1509/jmkg.74.5.18

Maignan, I. (1997). Antecedents and Benefits of Corporate Citizenship: a Comparison of U.S. and French Businesses. University of Memphis.

Mainieri, T., Barnett, E. G., Valdero, T. R., Unipan J. B., \& Oskamp, S. (1997). Green Buying: The influence of environmental concern on consumer behavior. The Journal of social psychology, 137, 189-204. http://dx.doi.org/10.1080/00224549709595430

Matthes, J., \& Wonneberger, A. (2014). The Skeptical Green Consumer Revisited: Testing the relationship between green consumerism and Skepticism toward advertising. Journal of advertising, 43, 115-127. http://dx.doi.org/10.1080/00913367.2013.834804

Mintu, A. T., \& Lozada H. R. (1993). Green Marketing Education: A Call for Action. Marketing Education Review, 3(Fall), 17-23.

Mitchell, C. Olsen, Rebecca, J. Slotergraaf, \& Sandeep, R. (2014). Chandukala. Green claim and Message Frames: How green New products Change Brand Attitude. Journal of Marketing, 78, 119-137.

Moloy Ghost. (2010). Green marketing. A changing concept in the changing time. BVIMR Management Edge, 4, $82-92$.

Pickett-Baker, Josephine, \& Ritsuko Ozaki. (2008). Pro-Environmental Products: Marketing Influence on Consumer Purchase Decision. Journal of Consumer Marketing, 25(5), 281-93.

Pogutz, S., Russo, A., \& Migliavacca, P. O. (2009). Innovation, markets and sustainable energy: The challenge of hydrogen and fuel cells. Edward Elgar Publishing.

Polonsky, Michael Jay. (1994). An introduction to Green Marketing. Electronic Green Journal, 1(2).

Pui Fong Ng, Muhammad Mohsin Butt, Kok Wei Khong, \& Fon Sim ONG. (2013). Antecedents of Green Brand Equity: An Integrated Approach. Springer Science Business Media Dordrecht.

Qazi Asif Zameer, \& Raj Devasagayam. (2015). Cognitive Dissonance and Buyers' Coping Mechanisms: A Comparative Study of US and Indian Consumers. International Journal of Business Administration, 6. http://dx.doi.org/10.5430/ijba.v6n3p1

Rettie, R., Burchell, K., \& Chris Barnham. (2014). Social normalisation: using marketing to make green normal. Journal of consumer bahaviour.

Sen, S., \& Bhattacharya, C. B. (2001). Does doing good always lead to doing better? Consumer reactions to corporate social responsibility. Journal of Marketing Research, $38(2)$. http://dx.doi.org/10.1509/jmkr.38.2.225.18838

Shrum, L. J., John A. McCarty, \& Tina M. Lowrey. (1995). Buyer Characteristics of the Green Consumer and Their Implications for Advertising Strategy. Journal of Advertising, 24(2), 71-82. http://dx.doi.org/10.1080/00913367.1995.10673477

Smith, K. T., \& Brower, T. R. (2012). Longitudinal study of green marketing strategies that influence Millenials. Journal of Strategic Marketing, 20(6). http://dx.doi.org/10.1080/0965254X.2012.711345

Spence Michael. (1973). Job Market Signaling. The Quarterly Journal of Economics, 87(3), 355-374.

Stanton, W. J., \& Futrell, C. (1987). Fundamentals of Marketing. McGraw-Ill. 
Tanese L. D., Rosca, M. I., \& Jurcoane, A. The perceptions on ecological products - a research on the urban consumer. From an ongoing doctoral research project of the University of Oradea.

Thorne, D., Ferrell, L., \& Ferrell, O. C. (2003). Business and Society: a strategic approach to corporate citizenship. Boston: Houghton Mifflin.

Tracy Tuten. (2013, April). Promoting sustainability by Marketing Green Products to Non-Adopters. Gestion 2000, 93-102. http://dx.doi.org/10.3917/g2000.302.0093

Trivedi, R. H., Patel, J. D., \& Savalia J. R. (2011). Pro- environmental Behavior of consumers: A Taxonomy and Its Implications for the Green Marketer. South Asian Journal of Management, 18, 121-133.

Vurro, C., Russo, A., \& Costanzo, L. A. (2014). Sustainability along the Value Chain: Collaborative Approaches and their Impact on Firm Performance. Symphonya, $2,1-15$. http://dx.doi.org/10.4468/2014.2.04vurro.russo.costanzo

Xie, Chaunyan, Bagozzi, Richard P., \& Gronhaug Kjell. (2014). The role of moral emotions and individual differences in consumer responses to corporate green and non-green actions. Journal of the academy of Marketing Science, 43, 333-356.

Zaharia, C., \& Zaharia I. (2014). The greening of consumer culture, Economics, Management, and Financial Markets, 9(1), 136-141. 